\title{
Gender as a Factor in the Physician and Patient Interaction: From the Service Quality Perspective
}

\author{
Versavel Tecleab Haile \\ Kaposvár University \\ Doctoral School of Management and Organizational Science \\ E-mail: versicho@gmail.com; Haile.Versavel@ke.hu
}

Received: 30 August 2018/ Revised: 6 November 2018/ Accepted: 11 November 2018/Published online: 21 December 2018

\begin{abstract}
Research has not yet adequately explored the potential interplay between the physician's gender and the patient's perception of the service quality. Although various studies have covered the measurement of service quality in the hospital industry, the gender perspective has not been touched on significantly. This study is a review article that aims to explore how gender matters to the physician-patient interaction in the service setting. It discusses the patient's responses to physicians of different genders and the behavior of physicians of different genders. Consequently, it was found that gender is one of the factors that influence the physician-patient interaction and patients' perception of the doctor's competence. The gender of the physician as well as the patient could influence the communication level in medical encounters. Gender-based stereotypes in the service encounter could also affect the patient-physician interaction and the evaluations that patients give to physicians. Moreover, it was discussed that traditions, religion, culture, stereotypes and past experience serve as a foundation for customers to form a preference for the physician's sex. The relationship between the physician and the patient is shaped by many factors lying on both the patient's and the doctor's side. These factors include the difference in communication style between males and females, the patient-physician gender dyad, the difference in personality traits between males and females. All these factors fall under the service dimension that is essential in measuring the quality of service.
\end{abstract}

JEL classification: M30, M31, I11

Keywords: gender, physician, patient, interaction, service quality, gender stereotype, communication.

\section{INTRODUCTION}

With a glimpse of thought, one might think that either masculine or feminine is the character that could best describe a physician. Which gender pops up in your mind first when you think of a doctor? This kind of question has been asked in the research to test how people instantly associate gender with the profession, which is commonly understood as "unconscious stereotypes" or "implicit bias". For example, Cao and Banaji (2016) revealed that the image of a female 
as a doctor was consciously fitted in the minds of people but unconsciously people still held a stereotype that associated a male with being a doctor and a female with being a nurse. When people are given male and female names and asked which one is a doctor and which one is a nurse, their conscious brain answers that both genders can be equally either a doctor or a nurse, but unconsciously they run a stereotype linking the male name with doctors and the female name with nurses. The authors gave another example of implicit biases by linking the scenario to the old riddle about a father and a son who are in a terrible car accident. The father dies, and the son is rushed to the hospital, where the surgeon takes one look and says, "I can't operate on this patient! He's my son". People answered to this statement saying that the surgeon could be the biological father of the boy and the father who died in the accident could be the foster dad who adopted the boy. However, the correct answer is that the surgeon is the mother of the boy. The big question is why people are conditioned into thinking that surgeons are men but not women.

Female physicians have been underestimated in their skills and are seen as less qualified in the profession when compared to male physicians. Different explanations could be given why this thought has been evolving over centuries. First, it could be because of the occupational segregation. Some professions are dominated by either males or females. For example, globally, nurses are dominantly women and doctors are dominantly men (WHO, 2006). Between 2001 and 2004, women represented 32\% of the physicians worldwide (WHO, 2013). A study in the USA showed that, although the number of women entering medical schools had increased over time, women physicians were less likely than men physicians to hold a leading position (Catalyst Research, 2013). It is a glaring fact that worldwide high-status jobs, in general, are dominated by males. As in other jobs, female physicians are faced with similar challenges in the medical field. Globally, nurses are dominantly women and senior positions like doctors are mainly dominated by men (WHO, 2006). For centuries in the medical discipline, doctors were perceived to be males but not females. "Masculinity" persisted as a brand for the medical profession until recently (Couch \& Sigler, 2001). Females in a male-dominated job may face stereotypes and their competence may be questioned. Likewise, males in a female-dominated job may feel intimidated and be prejudiced. Second, stereotypes could also stem from the distribution of male and female social roles. In societies marked by deep gender inequalities, women hold a lower position and are regarded as subordinates. Thus, women physicians in such societies experience stereotypes within the workplace and the society at large.

The quality of health services may have different dimensions such as geographic distribution of health facilities, accessibility, affordability, acceptability (Hausmann et al., 2003), tangibility, assurance, reliability, responsiveness, and empathy. However, the focus of this article is the communication part of the physician-patient interaction. Even with all the dimensions being met, communication could be a barrier in the physician-patient interaction, which would in turn affect the quality of service. The aim of this study is to indicate the impact of gender on the patient-physician interaction and consequently on the perception of service quality. In this paper, the research questions "How does gender affect the interaction between the physician and the patient?" and "Does the gender of the physician and patient matter to service quality?" will be addressed in two parts. In the first part, I will map the context of gender in the interaction between the physician and the patient (communication). In the second part, I will discuss how communication/interaction behavior differs between the genders for both patients and physicians, the gender dyad and satisfaction, gender stereotypes and lastly the patient's preference for the physician's gender. This paper is a review of literature focused on empirical studies conducted in the fields of general practice and internal medicine. It provides an exhaustive summary of existing evidence relevant to the research questions. Google Scholar, ResearchGate and Science Direct were mainly used to fetch articles. Key words like physician-patient interaction, gender stereotype, communication and service quality were used to narrow down the search. The titles and abstracts used in this review were checked against pre-determined criteria for eligibility and 
relevance to form an inclusion set that relates back to the research problem. Different medicine and psychology journals and databases were covered such as PubMed and PsyInfo. The articles reviewed are studies of the period 1974-2015.

\section{THEORETICAL BACKGROUND}

\section{Doctor-Patient Interaction}

The medical service outcome is at the best level when medical examination is accompanied by focused interpersonal relations such as showing more support and responding to the emotions of patients. When patients learn that their pain and feeling are being shared by the physician as a partner, they become more relieved and put trust in the physician. A good rapport can help bring about the desired and speedy recovery of a particular patient. The relationship between the doctor and the patient plays a significant role in healthcare delivery. As depicted in Figure 1, a medical visit has a major role in the process of care and has several inputs and outcomes. Both the physician and the patient bring in their own communication styles, attitudes, beliefs, expectations, and sociodemographic characteristics to the medical service encounter. The outcomes of a medical consultation include: utilization of healthcare resources, professional satisfaction, the physician's knowledge of the patient's problems and the patient's immediate (change in concern, satisfaction with the visit, and recall of information given), intermediate (adherence to recommendations), and long-term (change in health status) outcomes (Roter et al., 2009).

Figure 1.

Doctor-patient interaction inputs and outcomes

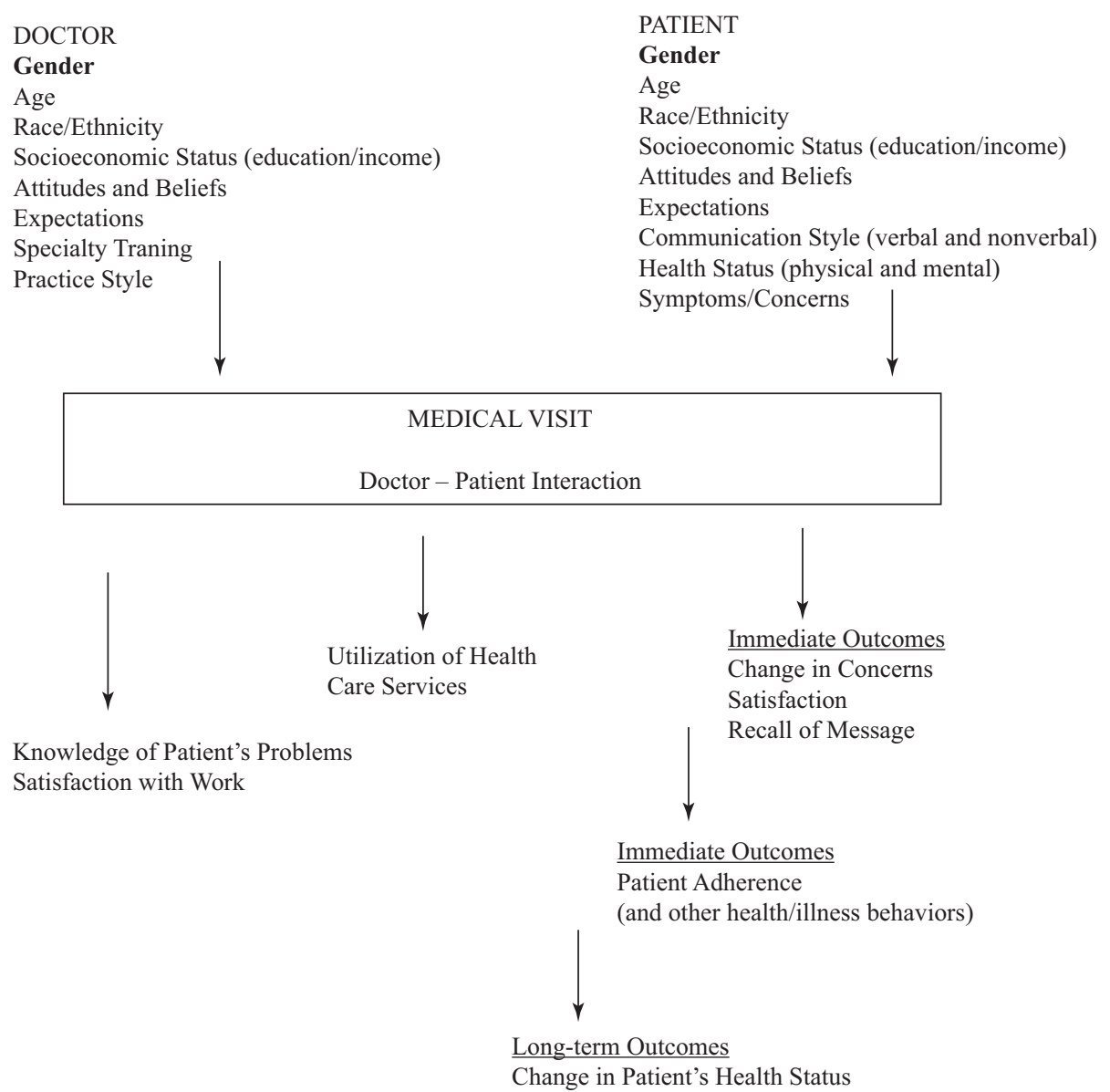




\subsection{Patient's Attitudes Towards the Physician's Sex}

Gender is one of the factors that influence the patient's perception of a doctor's competence. Couch and Sigler (2001) investigated how patients categorize specialties based on gender of the physician. In their study, respondents were given three categories: feminine, masculine and neutral. They were told to classify a list of medical specialties under each category. Based on the result, respondents were likely to perceive that occupations such as cardiologist, orthodontist, and surgeons were "masculine". Nurses and psychologists were perceived as "feminine" whereas dermatologists and psychiatrist were perceived as "neutral" specialties. Biased perceptions of medical professions such as classifying physicians based on their gender rather than their competence and associating gender with the specialties are the stereotypes mostly seen in the medical field. In the history of the medical profession, women have been regarded as less competent and less experienced than their male counterparts all because of the stereotypes that people hold towards women. For example, the studies of Decker (1986) and Engleman (1974) showed how female physicians were questioned for their skills and competence. Albrecht et al. (1977) also claimed that patients believed that males were better suited to be doctors than females. This belief was reflected by both adults and children. 5 to 10 years old children rated a female doctor as being less competent than a male doctor (Cann \& Garnett, 1984). Recent studies show that this biased perception and stereotypes have somehow diminished over time but have not totally vanished. For example, while male physicians are perceived to be more competent than female doctors, female physicians are rated with greater empathy and care for patients (Nicolai \& Demmel, 2007; Smith \& Dundes, 2007).

\section{DISCUSSION}

\subsection{Communication in the Medical Service Encounter}

Communication is one of the service quality dimensions on which customers base their evaluation and measurement. This dimension is very important to establish a good relationship with customers, impacting the overall service outcome in a positive way. Especially in the hospital industry, a good patient-physician relationship is one of the qualities used to measure the service quality. Patients expect their physician to initiate communication, build a relationship with them and maintain it in a comfortable and professional way. Everything being said, the gender of the physician could influence the communication level in medical encounters. I believe that gender is significantly related to communication and gender-based stereotypes in the service encounter could affect the patient-physician communication.

For example, first, basing on the physician's gender and the associated stereotype, patients may generate assumptions about the qualification and competence of the physician prior to the service encounter. It is common in public health centers that patients do not know the gender of the doctor until the first service experience. If the patient was expecting the doctor to be a man with the belief that man is the most competent for the service, the patient may be disappointed if the doctor happens to be a woman. The same applies to a patient who was expecting a woman physician and ends up with a man physician. Such incongruence may result in the discomfort of the patient in communicating with the physician. Patients may also show less attention to the comments and advice of the physician if they hold a stereotype that the doctor is incapable. Second, the gender of the physician affects the interaction in such a way that for treatments which need some sort of open discussion between partners and where patients need to expose their body including their private part, it is highly unlikely that patients prefer to visit the oppositesex physician. For instance, women patients would like their gynecologist to be a woman. If the 
doctor is male, the patient may be uncomfortable in discussing with the doctor. This could limit communication between the partners, which results in dissatisfaction of the patient.

\subsection{The Difference in Behavior Between Male and Female Physicians}

Since physician-patient communication can have a significant effect on the outcomes (e.g. satisfaction and health improvement) (Stewart, 1995), it is worth studying the possibility that the physician's gender may influence communication in the medical encounter. Male and female physicians show a considerable difference in behavior. Although the quality of medical information provided is similar between the two genders, a difference exists in how physicians interact with their patients. The difference is believed to be due to the behavioral practice of males and females. For example, female physicians show interest in socializing and building a relationship with their patients during consultations. They are more likely to share emotions and information, involve patients in a discussion, encourage them to express themselves, talk more, engage in participatory decision-making, building a partnership with patients (Roter et al., 2001), ask closed questions, show warmer behavior, display positive nonverbal communication, for example, nodding, smiling and a friendly tone of voice (Roter et. al., 2002), and they interrupt patients less than male physicians do (Rhoades, 2001). While male physicians are goal-oriented and tend to spend more time on discussing medical treatment issues as pros and cons of the treatment (Bertakis et al., 2003; Nicolai \& Demmel, 2007), studies of Franks and Bertakis (2003) and Roter and Hall (2004) indicated that women doctors spend much more time with their patients and communicate better than male doctors who seem to focus only on information concerning the illness and symptoms of patients.

Concerning the mechanics of physicians in diagnosing the patient, studies have shown that more of the preventive screening is done by female physicians than male physicians (Henderson \& Weisman, 2001; Rondeau et al., 2006). Women doctors are more likely to spend time on counseling patients. It has been reported that male physicians put more emphasis on biomedical aspects of illness and referrals for cardiac catheterization procedures than female physicians (Rathore et al., 2001). In sum, women physician exhibit patient-centered behavior that is more caring and sharing as they are in social relations or non-clinical populations (Roter \& Hall, 2004; Roter et al., 2002).

\subsection{Patient-Physician Gender Dyad in a Medical Encounter}

Gender has an influence on both ends of the physician and the patient. Physician-patient communication can also be associated with the patient's gender. Male and female patients exhibit different behavior during a medical examination. For instance, a female patient tends to interact more actively, ask more questions, express emotions freely, engage in partnership easily, show more interest. Male patients, on the other hand, feel reserved, less engage in discussion and talk more about facts only (Hall \& Roter, 1995; Stewart, 1983) Another interesting finding explains that male patients have shorter and less participatory visits when examined by a male doctor. Female patients showed a relatively longer visit when accommodated by female doctors (Kaplan, 1995). While consulting, physicians tend to display more emotional and egalitarian behaviors towards female patients than toward male patients. Moreover, physicians also show more dominant behaviors toward female patients than toward male patients (Hall \& Roter, 1995, 1998; Rhoades et al., 2001).

Because of the patient-centered communication shown by women physicians, patients consulted by a women physician have a closer relationship, show a more positive interaction such that they agree more, talk more, give more psychological information and medical information 
than when consulting a man physician. They also show positive nonverbal communication such as smiling and gazing. When compared to a male physician, patients of female physicians act in a dominant way, feel more empowered, interrupt conversations and ask more questions. All in all, women physicians' patients are more likely to be participative than male physicians' patients (Dindia \& Allen, 1992; Hall \& Roter, 1998).

Female physician-female patient dyad: As patients' behavior differs by sex, so does their satisfaction level with the sex of the physician. Female patients were more satisfied with a female physician than a male physician (Derose et al., 2001) and expressed more willingness to visit female physicians than male physicians (Shah \& Ogden, 2006). The dyad is characterized by longer consultation hours (Franks \& Bertakis, 2003), more intensive psychological discussions, eye contact (Van den Brink, 2002), equal amount of speaking time of the physician and the patient (Hall et al., 1994), more patient-centeredness (Law \& Britten, 1995), and more coordination of behaviors between the parties (Koss \& Rosenthal, 1997).

Women patients tend to perceive female physicians' behavior toward patients as having both technical and interpersonal qualities while male physicians were perceived by patients as either low on both dimensions or as only instrumental (Shapiro et al., 1983).

Female physician-male patient dyad: The interaction between a female physician and a male patient is characterized by uneasiness felt by both partners, higher incongruence and discordant behaviors. This can be explained by the stereotype associated with sex and position. A woman physician in a higher position and a male patient in a subordinate position challenge the sex-based stereotype (Carrard \& Mast, 2015).

Male physician-male patient dyad: This dyad is characterized by the shortest visit time, the willingness to openly disclose symptoms to a physician, power differences between the two parties where the male physician shows high verbal dominance over the male patient (Carrard \& Mast, 2015; Roter \& Hall, 1991), the shortest visit time and the highest level of the physician's verbal dominance.

Male physician-female patient dyad: This dyad accommodates the least amount of the physician's patient-centeredness (Law \& Britten, 1995).

\subsection{Patient-Physician Relationship and Satisfaction}

Since medical services are characterized by a high level of uncertainty and risk, patients assess the service quality on the basis of therapeutic value and doctor-patient relationship rather than professional knowledge (Berry \& Bendapudi, 2007). A well-constructed patient-physician relationship helps to resolve the patient's dilemmas and uncertainties in medical services.

The relationship between the physician and the patient is shaped by many factors lying on both the patient's and the doctor's side. The relationship is the result of interactions between both parties at the doctor's office (Bishop, 2009; Leventhal, 2008; Spake, 2009). These factors include the assessment of the physician's competence, psychological comfort level of the patient, empathy, the understanding capacity of the doctor, attention, kindness displayed by the doctor (Gruber \& Frugone, 2011; Winsted, 2000), privacy, confidentiality, as well as integrity. All these factors fall under the service dimension that is essential in measuring the quality of service. Research shows that age, gender or nationality of the physician may influence the relationship between the patient and the physician and, in effect, the results of treatment (Shaha \& Ogdenb, 2006).

Patient-centeredness has shown a positive outcome for patients as well as for physicians. Patients trust patient-centered physicians more, are more satisfied (Aruguete \& Roberts, 2000; Bensing et al., 2001) and comply better with the physician's comments and recommendations on the treatment. Consequently, qualities of female doctors such as the ability to behave in a patientcentered style, providing emotional support, positive talk, and partnership building have shown 
to be related to a positive outcome which could also lead to customer satisfaction (Ambady, N., LaPlante, D., et al., 2002; Ambady, N., Koo, J., et al., 2002; Aruguete \& Roberts, 2000; Bensing et al., 2001; Bertakis et al., 2000). If the patient-centeredness is indeed a major factor in determining patients' satisfaction, this would make female physicians' patients more satisfied than patients of male physicians. Unfortunately, that is not always the case. It does not guarantee that female physicians have more satisfied patients or a higher evaluation compared to male physicians due to stereotypes. Although it was reported that female physicians are more focused on patients' emotional concerns and patients treated by female physicians are more likely to show progress in their health (Franks \& Bertakis, 2003), there is only a very small significant difference in patient satisfaction between female physicians and male physicians with the difference favoring female physicians (Hall et. al., 2011). Here we can observe a paradox which can be explained by the stereotype (Carrard \& Mast, 2015). Now that we have seen evidence that women physicians' behavior and orientation are more regarded as interpersonal and patient-centered, which leads to a higher satisfaction of patients, it is clear that "stereotypes" take the role for underestimation and devaluation of women physicians.

\subsection{Gender Stereotypes and Patient Preference for the Physician's Gender}

A stereotype is what a person belonging to a specific group is typically like or how he/she behaves (Burgess \& Borgida, 1999; Heilman, 2001). For example, women are expected to be soft, sociable, caring, indecisive, emotional, weak, gentle, and nurturing whereas men are expected to be strong, bold, agentic, aggressive, and rational. If women behave in any masculine way, the gender prescriptive stereotypes overlap with the descriptive ones. Thus, women are expected to portray the behaviors that stereotypically match their sex but if they do not or probably show stereotypically male characteristics, they will get a negative feedback.

The lack-of-fit model (Heilman, 1983, 1995) is the state when the expectations about the characteristics of a job are congruent with the attributes stereotypically associated with the person in the job, and then the evaluation will be positive. However, when there is a lack of congruence between the characteristics associated with the job and those associated with the person, the evaluation of the person will be negative. The lack-of-fit model can be applied in the healthcare profession. Women are stereotypically seen as low in status but if a female physician who is expected to be low in status, caring and sociable behaves in a typically male way as powerful and agentic, she will be negatively evaluated. Thus, a female physician showing less patient-centered communication will receive a more negative evaluation and when she behaves in a typically female way, she is positively evaluated (Carrard \& Mast, 2015).

This argument is also supported by another finding. Patients reported more satisfaction with a female physician when her behavior matched what is stereotypically expected from her gender, i.e. softer and gazing. However, patient satisfaction ratings for male physicians seemed less dependent on their gender-congruent behavior (Schmid et al., 2008).

Evidence shows that (e.g. Hall et al., 2014) when women exhibit patient-centered behavior, they do not get credit for that because that is what they are expected to be. However, when they do not practice such behavior, they obtain an unfavorable evaluation. In contrast, men do get credit when exhibiting patient-centered behavior because it makes them seen as extraordinary or going the extra mile to accommodate their patients and this gets noticed by patients in a favorable way. This can be explained by the lack-of-fit model where the level of expected patient-centered behavior and the level of actually shown patient-centered behavior seem to be the driving factor for how patients evaluate their physicians.

Patriarchal societies marked by deep gender inequities also affect female physicians' interactions with their patients that consequently influence the output. Women physicians in such societies experience discrimination within the workplace and the society at large, which could be 
reflected in their interaction with their patients (Govender \& Penn-Kekana, 2008). For example, a qualitative study of the experience of female community-level workers in Pakistan reported the frustrations and discrimination that female workers face and their impact on their interaction with patients:

"When I leave home to come to the Basic Health Unit I need to travel by local transport, and there are men who offer a lift or pass comments. I feel so bad and insulted that when I reach the Basic Health Unit I misbehave with my patients" (Mumtaz et al., 2003, p. 264). Women physicians challenged with verbal assault in their workplace and community would not perform the service at their best, which could consequently negatively affect their service evaluation.

Patients, regardless of sex, often vary their responses depending on the physician's gender. Traditions, religion, culture and past experience serve as a foundation for customers to form preference for the physician's sex. These factors should not be forgotten when researching patient satisfaction with service quality as they significantly influence the patient's choice of physician. Patients preference for the physician's gender could be structured by norms such that the patient or his/her family may feel that it is unacceptable to see a healthcare worker of another sex (Govender \& Penn-Kekana, 2008). Gender concordance between the provider and the patient is important in highly patriarchal societies, where socio-cultural and/or religious norms and practices demarcate gender roles and restrict social and physical contact between men and women (Govender \& Penn-Kekana, 2008). For example, in some regions where Islam is strictly practiced, it is unlikely for a woman to go to a male doctor if she has to choose between a man and a woman. The cultural restriction on women not to interact with men makes it difficult for women patients to be diagnosed by a male physician. Clearly, the gender of the physician affects the patient's degree of comfort during medical examination, especially where a female patient has to go naked in front of a male physician. A qualitative study carried out in Cuba, Thailand, Saudi Arabia and Argentina examined the experiences of women seeking antenatal care and found that due to cultural reasons female doctors were more preferred by Saudi and Thai women (Arabia et al., 2003).

Another concern to be addressed in the patient's preference for the physician's gender is 'abuse'. The abuse of patients by healthcare providers is a critical issue that frames the relationship between the physician and the patient. A female patient who was abused in the past by her male physician would be less likely to visit a male physician again. The nature of the patient-provider interaction involves an intimate relationship, power, and control where the physician holds knowledge and access to the treatment that the patient seeks to regain health. With the cover of such power and superiority, the physician may take advantage of the patients. Especially women are vulnerable to sexual, verbal and physical abuse.

\section{CONCLUSION}

This paper has presented evidence that gender plays a role in the physician and patient interaction. It concludes that gender, either alone or in combination with other factors of service dimensions, influences interactions between the physician and patients. Female and male physicians exhibit somewhat different communication behavior in medical practice. Likewise, patients of different genders have different communication behavior and expectations of male and female physicians. Women physician are shown to have more patient-centered behavior than their male counterparts, which leads to a positive medical outcome and the patient's satisfaction. However, gender stereotypes hold women physician away from getting positive evaluation and feedback in their job. Occupational segregation and distribution of women and men in the social roles have resulted in implicit bias towards women physicians. The myth "doctors are men" has been persisting for centuries creating a demarcation in the profession. Women are more regarded as nurses than doctors and their skills are marginalized. However, as the women participation 
in the medical profession has increased and more patients are treated by a growing number of women physicians more than ever before, the patients' stereotypes and biases toward female physicians may eventually deteriorate. Negative evaluation of women physicians is mostly not because they lack the ability and competence but it has more to do with a lack-of-fit model and gender role incongruence. The image that women have in the society influences the level of their acceptance as physicians. Much of the gender discrimination in medical jobs is almost implicit or unconscious, reflecting the norms of the society in which both the health worker and the patient are based. By being made mindful of these biases and of how these inclinations result in workers giving distinctive treatment to various patients for no clinical reason, physicians may become more reflective about their practice. Physicians additionally should be made mindful of the sexual orientation elements that exist and affect how and when people need healthcare and how they discuss their problems and symptoms with physicians. Physicians should be mindful about the limitations that women face during a medical examination, mindful of how the process of the healthcare will affect women and mindful of the social stigma that is connected to the ailment of women, and this will empower them to provide better care (Thorson \& Johansson, 2004). Physicians likewise should be taught about issues around sexual maltreatment of patients and in addition the privileges of patients. Correspondingly, as much as it is important to get physicians to be more gender-sensitive, it is also critical to recognize the sex setting and gender context in which women physicians live and work. Respect from their male coworkers and a harassmentfree working zone could empower women physicians. Once esteemed, valued and respected, they will more likely provide a better quality of care service. It is also important to empower patients through a scope of techniques including educating them about their rights and raising awareness on how to stand against sexual and verbal abuses on the part of physicians.

Apart from stereotypes and expectations of patients, the physician-patient dyad could influence patient satisfaction. Same-sex physician-patient interactions are indicated to be characterized by more effective communication and stronger rapport than opposite-sex dyads. The physicianpatient interaction is one of the dimensions of medical service quality that comprises qualities more associated with communication. Patients evaluate the service quality on different grounds including their communicative interaction with their physician. Thus, gender plays a role in communication that would also affect the patient's perceived service quality. Sex cognizance and sensitization should be consolidated into the basic training of physicians that helps to better understand the sex dyads at medical encounters. A research gap exists as regards the impact of gender on the physician and patient interaction and the outcome of the service. The service quality literature has not adequately studied the area. This paper contributes to the scarce literature on the topic. However, this study analyzes only the communication dimension of a service. Hence, it cannot be generalized to all aspect of medical service quality. Further research is needed to investigate the other service dimensions of service quality (tangibility, responsiveness, empathy and reliability and assurance) and to explore the long-term and sustained impact of interventions. With all these dimensions being studied, a better understanding can be gained on how gender of a physician and patient affects service quality. Empirical research is needed to understand the reciprocal effect of the physician's gender-based behaviors in order to clarify if the behavioral differences in the communication styles of male and female physicians would result in a different behavior of patients that is directed back to the physician behavior. Finally, this study suggests gender diversity of the health workforce in medical care for a better quality of service and the patient's satisfaction. A gender integrating healthcare service enables the collective use of women's and men's potentials, knowledge, experience, and problem-solving skills, which has a positive effect on service quality.

The personality differences between men and women complement each other and yield a better output. Moreover, gender diversity helps avoid prejudice against women physicians and 
the perception that they are less competent than men. Policies designed to reduce discrimination against women physicians have to take the diversity aspects into consideration.

\section{References}

Albrecht, S.L., Bahr, H.M., \& Chadwick, B.A. (1977). Public stereotyping of sex roles, personality characteristics, and occupations. Sociology and Social Research, 61(2), 223-240.

Ambady, N., Koo, J., Rosenthal, R., \& Winograd, C.H. (2002). Physical therapists' nonverbal communication predicts geriatric patients' health outcomes. Psychology and Aging, 17, 443-452. doi: 10.1037/0882-7974.17.3.443 http://dx.doi.org/10.1037/0882-7974.17.3.443

Ambady, N., LaPlante, D., Nguyen, T., Rosenthal, R., Chaumeton, N., \& Levinson, W. (2002). Surgeons' tone of voice: A clue to malpractice history. Surgery, 132, 5-9. doi: 10.1067/msy.2002.124733

Arabia, S., Romero, M., Carroli, G., Nigenda, G., Langer, A., \& Kuchaisit, C. (2003, June). Women's opinions on antenatal care in developing countries: Results of a study in Cuba, Thailand, Saudi Arabia and Argentina. BMC Public Health, 12, 1-12. DOI:10.1186/1471-2458-3-17

Aruguete, M.S. \& Roberts, C.A. (2000). Gender, affiliation, and control in physician-patient encounters. Sex Roles, 42, 107-118. doi: 10.1023/A:1007036412480

Bensing, J., van Dulmen, S., Kallerup, H., Visser, A., Borrell, F., Finset, A., \& Zimmermann, C. (2001). The European Association for Communication in Healthcare. Patient Education and Counseling, 43, 1-4. doi: 10.1016/ S0738-3991(01)00125-2

Berry L.L. \& Bendapudi, N. (2007). Health care: A fertile field for service research. Journal of Service Research, 10(2), 111-122.

Bertakis K.D., Azari R., Callahan E.J., \& Robbins J.A. (2009). Gender differences in utilization of health care services. J Fam Practice, 49, 147-52.

Bertakis, K.D. (2009). The influence of gender on the doctor-patient interaction. Patient Education and Counseling, 76(3), 356-360. tic review.

Bertakis, D.K., Franks, P., \& Azari, R. (2003). Effects of physician gender on patient satisfaction. Journal of the American Medical Women's Association, 58(2), 69-75.

Bishop, D.V.M. (2009). Genes, cognition, and communication: Insights from neurodevelopmental disorders. Annals of the New York Academy of Sciences, 1156, 1-18. https://doi.org/10.1111/j.1749-6632.2009.04419.x

Burgess, D. \& Borgida, E. (1999). Who women are, who women should be: Descriptive and prescriptive gender stereotyping in sex discrimination. Psychology, Public Policy, and Law, 5, 665-692. doi: 10.1037/1076-8971.5.3.665

Cann, A. \& Garnett, A.K. (1984). Sex stereotype impacts on competence ratings by children. Sex Roles, 11(3/4), 333-343.

Carrard, V. \& Mast, M.S. (2015). The impact of gender stereotype in patient-physician interaction. In K. Faniko, F. Lorenzi-Cioldi, O. Sarrasin, \& E. Mayor (Eds.), Gender and social hierarchies: Perspectives from social psychology (pp. 1-21). UK: Routledge.

Catalyst Research. (2013). Pyramid: Women in U.S. healthcare. Retrieved from http://www.catalyst.org/knowledge/ women-us-healthcare

Couch, J.V. \& Sigler, J.N. (2001). Gender perception of professional occupations. Psychological Reports, 88(3), 693-698.

Decker, W.H. (1986). Occupation and impressions: stereotypes of males and females in three professions. Social Behavior and Personality, 14(1), 69-75.

Derose, K.P., Hays, R.D., McCaffrey, D.F., \& Baker, D.W. (2001). Does physician gender affect satisfaction of men and women visiting the emergency department? Journal of General Internal Medicine, 16(4), 218-226.

Dindia, K. \& Allen, M. (1992). Sex differences in self-disclosure: A meta-analysis. Psychological Bulletin, 112, 106-124. doi: 10.1037/0033-2909.112.1.106

Engleman, E.G. (1974). Attitudes toward women physicians: A study of 500 clinic patients. The Western Journal of Medicine, 120(5), 95-100.

Franks, P. \& Bertakis, K.D. (2003). Physician gender, patient gender, and primary care. J Womens Health, 12(1), 73-80.

Govender, V. \& Penn-Kekana, L. (2008). Gender biases and discrimination: A review of health care interpersonal interactions. Global Public Health, 3(SUPPL. 1), 90-103. DOI:10.1080/17441690801892208

Gruber, T. \& Frugone, F. (2011). Uncovering the desired qualities and behaviours of general practitioners (GPs) during medical (service recovery) encounters. Journal of Service Management, 22(4), 491-521.

Hall, J.A. \& Roter, D.L. (1995). Patient gender and communication with physicians: Results of a community-based study. Women's Health, 1, 77-95. 
Hall, J.A. \& Roter, D.L. (1998). Medical communication and gender: A summary of research. The Journal of GenderSpecific Medicine, 1, 39-42. doi: 10.1001/jama.288.6.756.

Hall J.A., Irish J.T., Roter D.L., Ehrlich C.M., \& Miller L.H. (1994). Satisfaction, gender, and communication in medical visits. Med Care, 32, 1216-31.

Hall, J.A., Roter, D.L., Blanch-Hartigan, D., Mast, M.S., \& Pitegoff, C.A. (2015). How patient-centered do female physicians need to be? Analogue patients' satisfaction with male and female physicians' identical behaviors. Health Communication, 30(9), 894-900. DOI:10.1080/10410236.2014.900892

Hausmann-Muela, S. \& Ribera, J.M. (2003). Recipe knowledge: A tool for understanding some apparently irrational behavior. Anthropology and Medicine, 10(1), 87-105.

Heilman, M.E. (1983). Sex bias in work settings: The lack of fit model. In B. Staw \& L. Cummings (Eds.), Research in organizational behavior (Vol. 5). Greenwich, CT: JAI.

Heilman, M.E. (2001). Description and prescription: How gender stereotypes prevent women's ascent up the organizational ladder. Journal of Social Issues, 57, 657-674. doi: 10.1111/0022-4537.00234

Heilman, M.E., Block, C.J., \& Martell, R.F. (1995). Sex stereotypes: Do they influence perceptions of managers? Journal of Social Behavior and Personality, 10, 237-252.

Henderson J.T. \& Weisman C.S. (2001). Physician gender effects on preventive screening and counseling: An analysis of male and female patients' health care experiences. Med Care, 39(12), 1281-92.

Kaplan, S.H., Gandek, B., Greenfield, S., Rogers, W., \& Ware, J.E. (1995). Patient and visit characteristics related to physicians' participatory decision-making style. Med Care, 33(12), 1176-87.

Law, S.A.T. \& Britten, N. (1995). Factors that influence the patient centredness of a consultation. British Journal of General Practice, 45(399), 520-524.

Leventhal, L. (2008). The role of understanding customer expectations in aged care. International Journal of Health Care Quality Assurance, 21(1), 50-59.

Mumtaz, Z., Salway, S., Waseem, M., \& Umer, N. (2003) Gender-based barriers to primary health care provision in Pakistan: the experience of female providers. Health Policy And Planning, 18(3), 261-269.

Nicolai, J. \& Demmel, R. (2007). The impact of gender stereotypes on the evaluation of general practitioners' communication skills: an experimental study using transcripts of physician-patient encounters. Patient Education and Counseling, 69(1-3), 200-205.

Rathore, S.S., Chen, J., Wang, Y., Radford, M.J., Vaccarino, V., \& Krumholz H.M. (2001). Sex differences in cardiac catheterization: The role of physician gender. JAMA, 286(22), 2849-56.

Rhoades, D.R., McFarland, K.F., Finch, W.H., \& Johnson, A.O. (2001). Speaking and interruptions during primary care office visits. Family Medicine, 33, 528-532.

Rondeau, K.V., Francescutti, L.H., \& Cummings, G.E. (2006). Health promoting attitudes and behaviors of emergency physicians: Exploring gender differences. J Health Organ Manag, 20(4), 269-84.

Roter, D.L. \& Hall, J.A. (1991). Health education theory: An application to the process of patient-provider communication. Health Education Research, 6(2), 185-193. DOI:10.1093/her/6.2.185

Roter, D.L. \& Hall, J.A. (2004). Physician gender and patient-centered communication: A critical review of empirical research. Annual Review of Public Health, 25(1), 497-519. DOI:10.1146/annurev. publhealth.25.101802.123134

Roter, D.L., Hall, J.A., \& Aoki, Y. (2002). Physician gender effects in medical communication: A meta-analytic review. Journal of the American Medical Association, 288, 756-764. doi: 10.1001/jama.288.6.756.

Roter, D.L. \& Larson, S. (2001). The relationship between residents' and attending physicians' communication during primary care visits: An illustrative use of the Roter interaction analysis system. Health Commun, 13, 33-48.

Schmid Mast, M., Hall, J.A., \& Roter, D.L. (2008). Caring and dominance affect participants'perceptions and behaviors during a virtual medical visit. Journal of General Internal Medicine, 23(5), 523-527. DOI:10.1007/ s11606-008-0512-5

Shah, R. \& Ogden, J. (2006). What's in a face? The role of doctor ethnicity, age and gender in the formation of patients' judgments: an experimental study. Patient Education and Counseling, 60(2), 136-141.

Shapiro, J., McGrath, E., \& Anderson, R.C. (1983). Patients', medical students', and physicians' perceptions of male and female physicians. Percept. Motor Skills, 56(1), 179-190.

Smith, M.K. \& Dundes, L. (2007). The implications of gender stereotypes for the dentist patient relationship. Journal of Dental Education, 72(5), 562-570.

Spake, D. \& Bishop, J. (2009). The impact of perceived closeness on the differing roles of satisfaction, trust, commitment, and comfort on intention to remain with a physician. Health Marketing Quarterly, 26(1), 1-15.

Stewart, M. (1983). Patient characteristics which are related to the doctor-patient interaction. Family Practice, 1, 30-36. doi: 10.1093/fampra/1.1.30

Stewart, M. (1995). Effective physician-patient communication and health outcomes: A review. Can Med Assoc J, $152(9), 1423-33$.

Thorson, A. \& Johansson, E. (2004) Equality or equity in health care access: A qualitative study of doctors' explanations to a longer doctor's delay among female TB patients in Vietnam. Health Policy, 68(1), 37-46. 
WHO. (2006). Working together for health: The World Health Report 2006. Geneva: World Health Organization.

WHO. (2013). Health workforce by gender distribution by country. Global Health Observatory Data Repository. Retrieved from http://apps.who.int/gho/data/node.main.A1449?lang=en

Winsted, K.F. (2000). Patient satisfaction with medical encounters: a cross-cultural perspective. International Journal of Service Industry Management, 11(5), 399-421. 